\title{
Pendidikan Keperawatan Berkelanjutan Dan Perencanaan Karir: Strategi Meningkatkan Komunikasi Interprofesional Yang Efektif
}

\author{
Nunung Rachmawati ${ }^{1}$ Luky Dwiantoro², Agus Santoso ${ }^{3}$ \\ ${ }^{1}$ Akademi Keperawatan "YKY" Yogyakarta \\ 2,3 Fakultas Kedokteran, Universitas Diponegoro, Semarang
}

\section{Informasi Artikel}

\section{Riwayat Artikel:}

Diterima 29 Desember 2017

\section{Kata Kunci:}

Komunikasi

Interprofesional; Pendidikan

Perawat; Rencana Karir

\section{PENDAHULUAN}

Distribusi serta perpaduan tenaga kesehatan yang belum merata menyebabkan pelayanan kesehatan terfragmentasi dan kebutuhan kesehatan masyarakat tidak terpenuhi, sehingga salah

\begin{abstract}
Kolaborasi interprofesional akan terwujud bila dua orang atau lebih dari profesi yang berbeda berinteraksi untuk menghasilkan pemahaman bersama yang tidak akan mungkin terjadi jika profesi tersebut bekerja sendiri-sendiri. Bagaimana masing-masing profesi memandang arti kolaborasi harus dipahami oleh kedua belah pihak sehingga dapat diperoleh persepsi yang sama.Penerapan kolaborasi antar profesi saat ini masih sebatas model kolaborasi tradisional atau multiprofesi.Tingkat pengetahuan yang tinggi diperlukan profesi keperawatan untuk dapat memberikan pelayanan keperawatan secara mandiri dan dapat berkolaborasi dengan tenaga kesehatan yang lain. Kesenjangan tingkat pendidikan dan pengetahuan inilah yang akan menghambat proses komunikasi yang efektif diantara profesi kesehatan Pendidikan keperawatan berkelanjutan dapat dijadikan salah satu strategi untuk menghilangkan kesenjangan pengetahuan dan pendidikan antar profesi tersebut sehingga akan meningkatkan proses komunikasi yang efektif diantara profesi kesehatan. Kolaborasi merupakan proses yang komplek yang membutuhkan perhatian khusus disertai dengan pengetahuan yang tinggi dalam melakukan tukar pikiran dalam mendiskusikan pasien. Perawat yang selalu berusaha meningkatkan pengetahuan dan keterampilan mereka untuk mencapai karir yang diinginkannya akan berdampak pada kemampuannya untuk bertukar pikiran (berkomunikasi) dengan profesi lainnya atau berkolaborasi dengan profesi lainnya. Pendidikan keperawatan berkelanjutan dan perencanaan karir merupakan dua strategi yang dapat meningkatkan pengetahuan dan keterampilan perawat sehingga akan meningkatkan kepercayaan diri perawat dalam bertukar pikiran dengan profesi lain.
\end{abstract}

satu solusi yang paling menjanjikan untuk mengatasi masalah kesehatan tersebut yaitu adalah interprofessional collaborative practice (Fatalina, Sunartini, Widyandana, \& Sedyowinarso, 2013). Kolaborasi interprofesional akan terwujud bila dua orang atau lebih dari profesi yang berbeda 
berinteraksi untuk menghasilkan pemahaman bersama yang tidak akan mungkin terjadi jika profesi tersebut bekerja sendiri-sendiri (LAM-PTKes, 2015). Selain itu yang perlu dipertimbangkan dalam pelaksanaan praktek kolaborasi interprofesional adalah ketersediaan sumber daya manusia yang berkualitas, adanya aturan atau regulasi, komitmen manajemen dan yang paling penting adalah adanya kemitraan atau kesetaraan.

Praktek kolaborasi interprofesional dapat menurunkan angka komplikasi, lama rawat di rumah sakit, konflik diantara tim kesehatan, dan tingkat kematian. Selain itu juga dapat meningkatkan kepuasan pasien dan tim kesehatan, mengurangi durasi pengobatan, mengurangi biaya perawatan, mengurangi insiden bunuh diri, dan mengurangi kunjungan rawat jalan (Fatalina et al., 2013).

Pelayanan kesehatan seharusnya tidak diberikan oleh tenaga kesehatan secara sendiri-sendiri, namun harus saling bersinergi dan berkolaborasi dalam sebuah tim. Pada kenyataanya, di beberapa rumah sakit besar di wilayah Indonesia belum terlihat kolaborasi tim yang setara dan kemitraan masih sekedar wacana. Perbedaan status antar profesi, adanya perasaan superior dan inferior serta banyaknya tindakan yang bersifat instruksi dari profesi lain masih mendominasi dan mengakar di dalam praktik kolaborasi (Fatalina et al., 2013). Bagaimana masingmasing profesi memandang arti kolaborasi harus dipahami oleh kedua belah pihak sehingga dapat diperoleh persepsi yang sama. Diperlukan adanya kesepakatan diantara tenaga kesehatan mengenai praktik kolaborasi interprofesi yang baik sehingga mutu pelayanan kesehatan dan kepuasan stakeholder dapat meningkat.

Penerapan kolaborasi antar profesi saat ini masih sebatas model kolaborasi tradisional atau multiprofesi. Model kolaborasi tradisional memandang salah satu profesi sebagai pemimpin tim dan pembuat keputusan, sedangkan profesi yang lain adalah sebagai pelaksanan dalam memberikan pelayanan ke pasien. Hal ini dapat terjadi karena adanya perbedaan cara pandang terhadap kolaborasi antar profesi. Salah satu profesi mungkin berpikir bahwa kolaborasi tersirat dalam bentuk tindak lanjut terkait dengan mengikuti instruksi atau perintah daripada saling berpartisipasi dalam pengambilan keputusan. Namun hal ini dipandang berbeda oleh profesi lain yang menganggap bahwa mereka sedang diperintah untuk melakukan sesuatu (Fatalina et al., 2013).

Perasaan superior dan inferiordari satu profesi terhadap profesi yang lain dalam praktek kolaborasi dapat terjadi karena adanya perbedaan tingkat pengetahuan dan pendidikan antar profesi yang dapat berdampak terhadap kemampuan anggota profesi dalam bertukar pikiran dengan profesi lainnya. Selain itu juga akan berdampak terhadap perbedaan interpretasi terhadap masalah kesehatan yang dialami pasien sehingga akan mempengaruhi kualitas penanganan yang diberikan (Fatalina et al., 2013). Kesenjangan tingkat pendidikan dan pengetahuan inilah yang akan menghambat proses komunikasi yang efektif diantara profesi kesehatan.Komunikasi yang efektif diantara profesi kesehatan merupakan salah satu unsur penting keberhasilan pelaksanaan praktek kolaborasi interprofesional. Menurut WHO (2009) 70 $80 \%$ kesalahan (error) dalam pelayanan kesehatan disebabkan oleh buruknya komunikasi dan pemahaman di dalam tim, kerjasama tim yang baik dapat membantu mengurangi masalah patient safety.

Tingkat pengetahuan yang tinggi diperlukan profesi keperawatan untuk dapat memberikan pelayanan keperawatan secara mandiri dan dapat berkolaborasi dengan tenaga kesehatan yang lain. Pengetahuan didapat dari proses pembelajaran baik secara formal maupun informal. Pembelajaran formal seperti Program Diploma 3 Keperawatan, Program S1 ilmu Keperawatan (PSIK), S2 Magister keperawatan, maupun S3 Keperawatan. Pembelajaran informal didapat dari pendidikan informal, seperti pembelajaran klinik, pelatihan khusus, seminar dan di 
dalam dunia kerja itu sendiri. Melalui pembelajaran tersebut baik secara formal maupun informal, perawat seharusnya mempunyai dasar yang kuat dari segi pengetahuan sehingga mampu bekerja berdampingan dan berkomunikasi secara efektif dengan tenaga kesehatan lainnya. Tingkat pengetahuan yang tinggi yang dimaksud tidak hanya sekedar pendidikan secara formal, tetapi lebih kepada kompetensi yang harus dimiliki seorang perawat, sehingga pendidikan keperawatan berkelanjutan inilah yang berfungsi menjembatani adanya gap kompetensi (kompetensi yang dimiliki dengan yang seharusnya dimiliki).

Menurut Siegler dan Whitney, kesenjangan yang terjadi antar profesi dapat terjadi karena pola pikir yang ditanamkan sejak awal proses pendidikan. Mahasiswa kedokteran pra-klinis sering terlibat langsung dalam aspek psikososial perawatan pasien melalui kegiatan tertentu. Selama periode tersebut hampir tidak ada kontak formal dengan para perawat, pekerja sosial atau profesional kesehatan lain. Sebagai praktisi memang mereka berbagi lingkungan kerja dengan para perawat tetapi mereka tidak dididik untuk menanggapinya sebagai kolega (Fatalina et al., 2013).

Kemampuan bekerjasama secara interprofesi (interprofessional teamwork) tidak muncul begitu saja, melainkan harus ditemukan dan dilatih sejak dini mulai dari tahap perkuliahan agar mahasiswa mempunyai bekal pengetahuan dan pengalaman mengenai cara bekerjasama secara tim yang baik dengan profesi lain sebelum mereka terjun ke dunia kerja (Wagner, Liston, \& Miller, 2011). Model pembelajaran pendidikan interprofesi atau interprofessional education yang selanjutnya disebut IPE dapat dijadikan suatu media pembelajaran bagi mahasiswa untuk belajar dan melatih kemampuan bekerjasama dengan profesi lain. IPE merupakan proses dimana sekelompok peserta didik atau tenaga kesehatan dengan latar belakang berbeda belajar bersama dalam jangka waktu tertentu pada masa pendidikan, dengan interaksi sebagai tujuan utamanya, untuk kolaborasi dalam menyediakan pelayanan preventif, promotif, rehabilitatif, dan pelayanan kesehatan lainnya (WHO, 2010).

Salah satu model IPE yang dapat diterapkan adalah simulasi IPE. Melalui simulasi IPE tersebut mahasiswa dapat mengembangkan pengetahuan dan keterampilan dalam berkomunikasi dengan profesi yang lain. Selain itu mahasiswa juga lebih percaya diri untuk berkomunikasi dengan profesi yang lain ketika berkolaborasi dengan profesi yang lain karena mahasiswa sudah memiliki bekal pengalaman sebelumnya. Wagner (2011) menjelaskan dalam penelitiannya yang berjudul "Developing Interprofessional Communication Skills" bahwa simulasi IPE sangat efektif dan diterima dengan baik sebagai inovasi dalam pembelajaran mahasiswa kesehatan. Simulasi tersebutmerupakan langkah awal menuju pengembangan budaya yang menumbuhkan kerja sama tim interprofessional dalam perawatan kesehatan. Selain itu, simulasi tersebut adalah cara untuk meningkatkan kualitas pelayanan kesehatan melalui pengembangan kolaborasi interprofesi, karena memberikan kesempatan setiap kelompok untuk belajar berinteraksi dengan profesi yang lain (CHFC-IPE, 2014).

\section{Komunikasi: Aspek Penting Kolaborasi}

Data penelitian menunjukkan bahwa beberapa elemen penting kolaborasi dalam pelaksanaan kolaborasi interprofesi yang meliputi komunikasi, koordinasi, tanggungjawab dan mutual trust (Fatalina, Sunartini, Widyandana, \& Sedyowinarso, 2015). Elemen kolaborasi ini sangat penting, tetapi dalam penerapannya masih mengalami banyak hambatan, antara lain masih minimnya komunikasi yang terjalin diantara anggota profesi. Hal ini disebabkan oleh adanya sikap egosentris dari profesi tertentu, minimnya waktu interaksi yang dimiliki oleh profesi tertentu serta munculnya stereotyping antar profesi. Hal ini sesuai dengan pernyataan dari CrossSudworth yang mengungkapkan bahwa komunikasi adalah salah satu aspek terpenting dalam kolaborasi interprofesi (Fatalina et al., 2015).Tanpa komunikasi yang efektif dan tepat, perawatan pasien 
seperti kehilangan hubungan manusia dan hanya mengandalkan pada stereotyping dan dugaan semata.

Komunikasi interprofesi yang sehat menimbulkan terjadinya pemecahan masalah, berbagai ide, dan pengambilan keputusan bersama (Potter \& Perry, 2005). Menurut O"Daniel and Rosenstein komunikasi tidak efektif terjadi di antara profesi kesehatan, keselamatan pasien menjadi taruhannya. Beberapa alasan yang dapat terjadi yaitu kurangnya informasi yang kritis, salah mempersepsikan informasi, perintah yang tidak jelas melalui telepon, dan melewatkan perubahan status atau informasi (CHFC-IPE, 2014).

Kendala komunikasi antar profesi kesehatan kerap memicu medication error atau kesalahan penanganan medis yang merugikan pasien. Salah satu pemicunya, beberapa profesi kesehatan seringkali merasa lebih superior dibanding profesi lainnya. Seluruh profesi kesehatan seharusnya bisa menyatukan visi misi dan memiliki kerja tim yang baik, sehingga keselamatan pasien pun terjaga. Keselamatan pasien merupakan proritas semua praktisi kesehatan.

Di dalam lingkungan kerja, perawat dan tim kesehatan membutuhkan interaksi social dan terapeutik untuk membangun kepercayaan dan memperkuat hubungan. Semua orang memiliki kebutuhan inter pribadi akan penerimaan, keterlibatan, identitas, privasi, kekuatan dan kontrol, sertaperhatian. Perawat membutuhkan persahabatan, dukungan, bimbingan, dan dorongan dari pihak lain untuk mengatasi tekanan akibat stress pekerjaan dan harus dapat menerapkan komunikasi yang baik dengan klien, sejawat dan rekan kerja (Potter \& Perry, 2009). Hambatan lain dalam berkomuniksi dengan tim kesehatan lain adalah menjadi emosional daripada berfokus pada masalah, menyalahkan orang lain, tertutup dan tidak menghargai serta memahami perspektif orang lain (Arnold \& Boggs, 2007).

Keberhasilan dari komunikasi yang efektif antara tim kesehatan bergantung pada hubungan baik di antara tenaga kesehatan. Keberhasilan kerja kelompok bergantung pada hubungan baik di antara anggota tim, terutama antara pemimpin tim dengan anggota tim lainnya. Pemimpin tim memiliki fungsi yaitu, mendorong terjadinya komunikasi, mengamati proses komunikasi yang terjalin, serta memberi perhatian kepada semua anggota agar komunikasi berjalan dengan efektif. Komunikasi interprofesi merupakan faktor yang sangat berpengaruh dalam meningkatkan keselamatan pasien, karena melalui komunikasi interprofesi yang berjalan efektif, akan menghindarkan tim tenaga kesehatan dari kesalahpahaman yang dapat menyebabkan medical error (Berridge, Mackintosh, \& Freeth, 2010).

\section{Pendidikan Keperawatan Berkelanjutan}

Pendidikan

keperawatan

berkelanjutan dapat dijadikan salah satu strategi untuk menghilangkan kesenjangan pengetahuan dan pendidikan antar profesi tersebut sehingga akan meningkatkan proses komunikasi yang efektif diantara profesi kesehatan (Waluya, N, 2010). Pendidikan berkelanjutan bagi perawat merupakan proses pengembangan keprofesian yang meliputi berbagai kegiatan yang dilakukan seseorang dalam kapasitasnya sebagai seorang perawat praktisi guna mempertahankan dan meningkatkan profesionalismenya sebagai seorang perawat sesuai standar kompetensi yang ditetapkan (PPNI, 2012).Pendidikan berkelanjutan merupakan salah satu ciri khas dari regulasi profesional, sehingga jika perawat ingin diakui sebagai profesional, harus berusaha dan menunjukkan keinginannya untuk terus belajar (PPNI, 2012).

ANMC menjelaskan bahwa pendidikan berkelanjutan menawarkan kesempatan bagi perawat dalam memelihara, meningkatkan dan memperluas pengetahuan, keahlian, serta mengembangkan kualitas pribadi dan profesionalitas yang diperlukan bagi perawat (Ross K, Barr J, 2013). Mengikuti pendidikan berkelanjutan adalah sebagai wujud tanggungjawab perawat terhadap 
profesi keperawatan dan untuk mempertahankan dan meningkatkan kompetensi profesional setiap perawat sesuai dengan perkembangan ilmu pengetahuan dan teknologi di bidang kesehatan / keperawatan, agar tetap dapat melaksanakan tugas berorientasi pada mutu dan keselamatan pasien.

Pendidikan berkelanjutan sangat penting untuk mempertahankan dan memperbaharui pengetahuan dasar (Bolderston, 2007). Pendidikan berkelanjutan juga diyakini dapat membantu praktisi dalam menggabungkan antara pengetahuan dan keterampilan untuk meningkatkan praktek secara profesional dan berfokus pada perawatan pasien (Patient Canter Care). ("Report on the Continuing Professional Development of Staff Nurses and Staff Midwives," 2004) Pendidikan berkelanjutan juga dapatmeningkatkan kepercayaan diri perawat dan motivasi, meningkatkan kesempatan jaringan dan peningkatan sumberdaya komitmen organisasi (Cleary, Horsfall, Hara, Jackson, \& Hunt, 2011).

Pendidikan berkelanjutan bagi perawat bertujuan untuk mempertahankan kompetensi dan memperkenalkan keterampilan baru yang diperlukan dalam pelaksanaan praktik keperawatan. Standar kompetensi perawat merefleksikan kompetensi yang harus dimiliki oleh perawat untuk memberikan asuhan keperawatan profesional. Standar kompetensi perawat Indonesia setara dengan standar internasional. Dengan demikian perawat Indonesia mendapatkan pengakuan yang sama dengan perawat dari negara lain.

Berdasarkan standar kompetensi perawat Indonesia, salah satu kompetensi yang harus dimiliki perawat (ners) adalah pengembangan kualitas personal dan profesional yang dilakukan dengan pendidikan berkelanjutan. Dengan pendidikan berkelanjutan maka diharapkan perawat (ners) mempunyai kompetensi untuk melakukan kajian secara teratur tentang praktik yang dilaksanakannya dengan cara refleksi, telaah kritis, dan evaluasi serta peer review, bertanggung jawab untuk belajar seumur hidup, pengembangan profesional dan meningkatkan kompetensi yang dimilikinya, belajar bersama orang lain untuk memberikan kontribusi terhadap pelayanan kesehatan (PPNI, AIPNI, \& AIPDiKI, 2012).

Dengan pendidikan berkelanjutan maka diharapkan perawat dapat meningkatkan pengetahuan dan kompetensi yang dimilikinya sehingga dapat meningkatkan rasa percaya dirinya dalam berkolaborasi dengan profesi lain. Kolaborasi merupakan proses yang komplek yang membutuhkan perhatian khusus disertai denganpengetahuan yang tinggi dalam melakukan tukar pikiran dalam mendiskusikan pasien. Komunikasi adalah salah satu elemen penting dari kolaborasi, jadi dengan meningkatnya pengetahuan dan kompetensi perawat melalui pendidikan berkelanjutan diharapkan perawat mempunyai kepercayaan diri untuk melakukan komunikasi yang efektif dan bertukar pikiran dengan profesi kesehatan lainnya.

\section{Rencana Karir}

Seorang perawat berperan dalam melakukan perencanaan karir pribadinya. Dengan perencanaan karir membuka jalan bagi perawat yang potensial, perencanaan karier memberikan keberanian kepada perawat untuk melangkah dan memajukan kemampuan potensial mereka karena mereka mempunyai tujuan karier yang spesifik, dapat memberikan performansi yang lebih baik untuk pekerjaannya sekarang ini. Perawat bertanggung jawab untuk terus meningkatkan keterampilan dan pengetahuan yang perawat miliki untuk memastikan bahwa dirinya mempunyai kompetensi yang sesuai dengan kebutuhan stakeholder. Perawat mengambil perencanaan karir di tangan mereka sendiri, memutuskan apa yang mereka ingin lakukan dan apa yang baik untuk mereka, investasi dalam diri mereka untuk mengembangkan keterampilan yang diperlukan. Untuk itulah, ada baiknya 
seorang perawat senantiasa dapat melakukan penilaian diri untuk mengenal karir yang dia inginkan, mengukur kekuatan yang ia miliki dan hal-hal yang perlu ditingkatkan lebih baik lagi. Dengan perencanaan karir pribadi ini, seorang perawat dapat menilai tingkat kesesuaian antara karir yang diinginkan dan karir yang dipegangnya saat ini. Dengan demikian dapat mengarahkan dirinya untuk memilih penugasan atau pekerjaan-pekerjaan yang lebih sesuai dengan karir yang diinginkan.

Konsep perencanaan karir sudah dilakukan oleh rumah sakit di Jepang ketika melakukan rekruitmen dan seleksi perawat baru. Perawat baru diharuskan membuat rencana karir (career planning) untuk mengenal karir yang diinginkannya sebagai seorang perawat kedepannya.

Dengan perencanaan karir yang dibuat maka diharapkan perawat baru akan selalu meningkatkan pengetahuan dan keterampilannya untuk mencapai karir yang diinginkan baik melalui pendidikan, pelatihan, seminar ataupun yang lainnya. Dengan perencanaan karir yang dibuat oleh perawat baru juga dapat menjadi dorongan bagi mereka untuk bekerja di rumah sakit karena memberikan kesempatan bagi mereka untuk lebih maju atau mencapai karir sesuai dengan yang diinginkan. Perawat yang selalu berusaha meningkatkan pengetahuan dan keterampilan mereka untuk mencapai karir yang diinginkannya akan berdampak pada kemampuannya untuk bertukar pikiran (berkomunikasi) dengan profesi lainnya atau berkolaborasi dengan profesi lainnya. Sehingga secara tidak langsung konsep perencanaan karir yang dibuat untuk perawat baru dapat menjadi salah satu faktor pendukung keberhasilan pelaksanaan kolaborasi dan komunikasi interprofesional.

\section{KESIMPULAN}

Tingkat pengetahuan yang tinggi diperlukan profesi keperawatan untuk dapat memberikan pelayanan keperawatan secara mandiri dan dapat berkolaborasi dengan tenaga kesehatan yang lain.
Pengetahuan didapat dari proses pembelajaran baik secara formal maupun informal. Melalui pembelajaran tersebut baik secara formal maupun informal, perawat seharusnya mempunyai dasar yang kuat dari segi pengetahuan sehingga mampu bekerja berdampingan dan berkomunikasi secara efektif dengan tenaga kesehatan lainnya.Komunikasi yang efektif diantara profesi kesehatan merupakan salah satu unsur penting keberhasilan pelaksanaan praktek kolaborasi interprofesional. Pendidikan keperawatan berkelanjutan dan perencanaan karir merupakan dua strategi yang dapat meningkatkan pengetahuan dan keterampilan perawat sehingga akan meningkatkan kepercayaan diri perawat dalam bertukar pikiran dengan profesi kesehatan lain.

\section{DAFTAR PUSTAKA}

Arnold, \& Boggs. (2007). Interpersonal relationships: professional communication skill for nurses. Missouri: Saunders elsevier.

Berridge, E. J., Mackintosh, N. J., \& Freeth, D. S. (2010). Supporting patient safety: examining communication within delivery suite teams through contrasting approaches to research observation. Retrieved March 8, 2012, from Available

at:http://www.ncbi.nlm.nih.gov/pubmed/206 96506

Bolderston, A. (2007). Maintaining competence: a holistic view of continuous professional development. J Radiother Pract, 6, 133-142.

CHFC-IPE, T. (2014). Buku Acuan Umum CFHC-IPE. Yogyakarta: Fakultas Kedokteran, UGM.

Cleary, M., Horsfall, J., Hara, M., Jackson, D., \& Hunt, G. (2011). The views of mental health nurses on continuing professional development. J Clin Nurs, 20.

Fatalina, F., Sunartini, Widyandana, \& Sedyowinarso, M. (2015). Persepsi dan Penerimaan Interprofessional Collaborative Practice Bidang Maternitas pada Tenaga Kesehatan. Jurnal Pendidikan Kedokteran Indonesia, 4.

Fatalina, Sunartini, Widyandana, \& Sedyowinarso. (2013). Persepsi dan Penerimaan 
Interprofessional Collaborative Practice Bidang Maternitas pada Tenaga Kesehatan. Jurnal Pendidikan Kedokteran Indonesia, 4, 141.

LAM-PTKes. (2015). Pendidikan Interprofesional Sebagai Pemicu Kolaborasi Interprofesional di Fasilitas Pelayanan Kesehatan. Retrieved from http://dev.lamptkes.org/berita/detail/49

Potter, \& Perry. (2009). Fundamental Keperawatan. Jakarta: Salemba Medika.

PPNI, AIPNI, \& AIPDiKI. (2012). Standar Kompetensi Perawat Indonesia. Jakarta.

PPNI, P. P. (2012). Kep PP-PPNI No 0962012 Pedoman PKB Perawat Indonesia.

Report on the Continuing Professional Development of Staff Nurses and Staff Midwives. (2004). National Council for the Professional Development of Nursing and Midwifery.

Ross K, Barr J, S. J. (2013). Mandatory continuing professional development requirements: what does this mean for Australian nurses. BioMedCentral Nurs., 12, 9-15.

Wagner, J., Liston, B., \& Miller, J. (2011). Developing interprofessional communication skills. Teaching and Learning in Nursing. Retrieved March 25, 2012, from Available at: http://linkinghub.elsevier.com/retrieve/pii/S 1557308710001149

Waluya, N, A. (2010). Trend dan Issue Keperawatan. Retrieved from pkko.fik.ui.ac.id/files/kolaborasi perawat dan dokter.doc

WHO. (2010). Framework for Action on Interprofessional Education and Collaborative Practice. Geneva: World Health Organitazion. 